\section{A) Check for updates}

Cite this: Polym. Chem., 2020, 11 560

Received 5th September 2019, Accepted 1st October 2019

DOI: 10.1039/c9py01335k

rsc.li/polymers

\title{
Facile terminal functionalization of peptides by protease-catalyzed chemoenzymatic polymerization toward synthesis of polymeric architectures consisting of peptides $\uparrow$
}

\begin{abstract}
Kousuke Tsuchiya (D) * and Keiji Numata (D) *
Polypeptides are used as building blocks that assemble into polymeric hierarchical architectures with various functionalities based on their amino acid sequences. Chemoenzymatic polymerization using a protease as a catalyst allows us to synthesize peptides with various primary structures in an environmentally benign way. In this work, we performed papain-catalyzed polymerization in the presence of terminal-modifying agents to synthesize peptides modified with a functional group at their $\mathrm{N}$-terminus. Various peptides with a reactive acrylamide group at the $\mathrm{N}$-terminus were synthesized in a one-pot chemoenzymatic reaction with the side groups of the amino acid residues left intact. Acrylamide-modified poly(L-alanine) was used as a macromonomer in a radical copolymerization with $\mathrm{N}$-isopropylacrylamide to give a graft copolymer consisting of poly(L-alanine) side chains.
\end{abstract}

\section{Introduction}

Polypeptides consisting of proteinogenic amino acids, which naturally exist as proteins, are fascinating biobased polymeric materials. The versatility of amino acid sequences expands the application of polypeptides, including as commodities, cosmetics, medicines, and biomedical materials. The physical properties of polypeptides are associated with their higherorder structures formed by self-assembly of the polypeptide backbone via inter-/intramolecular interactions such as hydrogen bonding and hydrophobic effects regulated by specific amino acid sequences. To take advantage of this unique advantage of polypeptides, much effort has been made to assemble peptide building blocks into polymeric architectures for functionalization.

Polypeptide-based building blocks are synthesized by various methods, including solid-phase peptide synthesis (SPPS) ${ }^{1}$ ring-opening polymerization of amino acid $\mathrm{N}$-carboxyanhydrides (NCAs), ${ }^{2,3}$ and biosynthesis using microbial hosts. ${ }^{4,5}$ The amino acid sequences of polypeptides can be easily regulated by SPPS and biosynthesis; however, tedious synthetic protocols make it difficult to produce the desired polypeptides in sufficient yield and purity and on a

Biomacromolecules Research Team, RIKEN Center for Sustainable Resource Science, 2-1 Hirosawa, Wako-shi, Saitama 351-0198, Japan. E-mail: kosuke.tsuchiya@riken.jp, keiji.numata@riken.jp

$\dagger$ Electronic supplementary information (ESI) available. See DOI: 10.1039/ C9PY01335K large scale. In addition, the ring-opening polymerization of NCAs has been widely utilized for the synthesis of polypeptides that are well-defined in terms of molecular weight and polydispersity. This method allows us to synthesize block copolymers consisting of two or more different polypeptide building blocks. Block copolymers based on polypeptides are widely used to construct well-defined molecular assemblies such as polymer micelles and hydrogels, mainly for drug delivery, regenerative medicines, and tissue engineering. ${ }^{6-11}$ Polypeptide fragments have also been assembled into special-shaped polymers such as graft copolymers and star-shaped polymers. ${ }^{12-14}$

Recently, chemoenzymatic polymerization using a protease as a catalyst has emerged as another method for synthesizing peptides. ${ }^{15,16}$ Chemoenzymatic polymerization employs kinetically controlled tandem aminolysis reactions of amino acid derivatives in an aqueous buffer solution, which offers atomeconomical, environmentally benign synthesis of polypeptides under mild conditions. ${ }^{15,17}$ The protease-catalyzed reaction provides stereo- and regioselectivity for the formation of peptide bonds. We have developed various types of peptides with homo-/random sequences by chemoenzymatic polymerization. ${ }^{16,18}$ Furthermore, poor substrate specificity for unnatural amino acids can be mitigated by modification with natural ones that show good affinity for proteases, resulting in successful introduction of unnatural structures such as nonproteinogenic amino acids, ${ }^{19,20}$ nylon units, ${ }^{21,22}$ telechelic structures, ${ }^{23,24}$ and aromatics ${ }^{25}$ in the peptide backbones. Peptides with a star-shaped structure were also synthesized using multifunctional substrates. ${ }^{26,27}$ 
Previously, we designed artificial polypeptide materials that mimic the higher-order structures of natural structural proteins by conjugating oligomeric peptide fragments. Specific amino acid motifs of structural proteins that govern their physical properties were derived from the sequence of structural proteins for this purpose. For example, we synthesized a $\beta$-sheet crystalline motif and glycine-rich amorphous motif of spider silk proteins ${ }^{28}$ and a repetitive motif of elastin ${ }^{29}$ that confers elasticity to polypeptides by chemoenzymatic polymerization. The peptide fragments were further conjugated into multiblock polypeptides, which showed specific secondary structures similar to those of natural proteins. Such peptide fragments can also be conjugated with synthetic polymers for biomimetic materials, as reported in some studies. ${ }^{30,31}$ The conjugation of peptide fragments has been performed by direct condensation, which requires relatively harsh conditions, in previous works. In this work, several types of peptides containing a reactive functional group that can be used for facile conjugation to construct special polymeric architectures were synthesized by papain-catalyzed polymerization. A terminal-modifying agent, which is expected to be involved in the polymerization reaction, was successfully introduced into a reactive functional group at the $\mathrm{N}$-terminus of the peptides. The functional group was then used for postpolymerization to construct polymeric architectures such as graft copolymers.

\section{Experimental}

\section{Materials}

Papain was purchased from FUJIFILM Wako Pure Chemical Industries, Ltd (Osaka, Japan) and used as received. The activity was approximately $0.5 \mathrm{U} \mathrm{g}^{-1}$, where one unit is defined as the amount of enzyme needed to hydrolyze $1 \mathrm{mmol}$ of $N$-benzoyl-DL-arginine $p$-nitroanilide per minute at $\mathrm{pH} 7.5$ and $25{ }^{\circ} \mathrm{C}$. Amino acid esters were purchased from Watanabe Chemical Industries, Ltd (Hiroshima, Japan) and used as received. $N$-Isopropylacrylamide (NIPAm) purchased from FUJIFILM Wako Pure Chemical Industries, Ltd was purified by recrystallization from hexane and stored at $-4{ }^{\circ} \mathrm{C}$ until use. $N, N$-Dimethylformamide and triethylamine were dried over $4 \AA$ molecular sieves and stored under nitrogen. All other reagents were purchased from Tokyo Chemical Industry Co., Ltd (Tokyo, Japan) and used as received without any purification unless otherwise noted.

\section{Analysis}

${ }^{1} \mathrm{H}$ and ${ }^{13} \mathrm{C}$ nuclear magnetic resonance (NMR) spectra were recorded on a Varian NMR System 500 (Varian Medical Systems, Palo Alto, CA) at $25{ }^{\circ} \mathrm{C}$ and at a frequency of $500 \mathrm{MHz}$. Dimethylsulfoxide- $d_{6}\left(\mathrm{DMSO}-d_{6}\right)$ with trifluoroacetic acid- $d$ (TFA- $d$ ) (5/1 in volume) was used as the solvent for the polypeptides with tetramethylsilane as an internal standard. Matrix-assisted laser desorption/ionization time-of-flight mass spectrometry (MALDI-TOF MS) analysis was conducted using an ultrafleXtreme MALDI-TOF spectrophotometer (Bruker
Daltonics, Billerica, MA) operating in reflection mode at an accelerating voltage of $15 \mathrm{kV}$. The sample was dissolved in water/acetonitrile $\left(0.8 \mathrm{mg} \mathrm{mL}^{-1}\right)$ containing $0.1 \%$ TFA, mixed with a solution of $\alpha$-cyano-4-hydroxycinnamic acid (CHCA) in water/acetonitrile $\left(10 \mathrm{mg} \mathrm{mL}^{-1}\right)$, and deposited on an MTP 384 ground steel $\mathrm{BC}$ target plate. Infrared (IR) spectra of the samples were recorded by an IRPrestige-21 Fourier transform infrared spectrophotometer (Shimadzu Corporation, Kyoto, Japan) with a MIRacle A single reflection ATR unit using a Ge prism. Gel permeation chromatography (GPC) was performed on a JASCO HPLC system (PU-2086, DG2080-54, AS-2057, CO-2065; JASCO, Tokyo, Japan) with a Shodex KD-804 column (Showa Denko K. K., Tokyo, Japan) and a UV detector (UV-2075). Measurements were carried out on polypeptide samples $\left(2 \mathrm{mg} \mathrm{mL} \mathrm{mL}^{-1}\right.$ ) eluted with NMP containing $10 \mathrm{mM}$ lithium bromide at a flow rate of $1.0 \mathrm{~mL} \mathrm{~min}^{-1}$. The number$\left(M_{\mathrm{n}}\right)$ and weight-average molecular weights $\left(M_{\mathrm{w}}\right)$ and the molecular weight distribution $\left(M_{\mathrm{w}} / M_{\mathrm{n}}\right)$ were estimated using polystyrene standards of the following molecular weights: $1.32 \times$ $10^{3}, 3.25 \times 10^{3}, 1.01 \times 10^{4}, 2.85 \times 10^{4}, 6.60 \times 10^{4}$, and $1.56 \times$ $10^{5}$. Circular dichroism (CD) spectroscopic analysis was conducted using a Jasco J-820 CD spectropolarimeter (JASCO, Tokyo, Japan). Measurements were conducted on polymer solutions $(0.05 \mathrm{w} / \mathrm{v} \%)$ in Milli-Q water using a quartz cuvette with a $1 \mathrm{~mm}$ path length. Each spectrum represents the average of 10 scans from 190 to $290 \mathrm{~nm}$ with a resolution of $1 \mathrm{~nm}$ obtained at $200 \mathrm{~nm} \mathrm{m^{-1 }}$ with a bandwidth of $1 \mathrm{~nm}$.

\section{Synthesis of $\mathrm{N}$-acryloyl-L-alanine ethyl ester (1)}

To a flask equipped with an addition funnel and a stirring bar were added L-alanine ethyl ester hydrochloride (4.61 g, $30.0 \mathrm{mmol})$, triethylamine $(9.2 \mathrm{~mL}, 66.0 \mathrm{mmol})$ and chloroform $(50 \mathrm{~mL})$ at $0{ }^{\circ} \mathrm{C}$ under nitrogen. To this solution, a solution of acryloyl chloride $(2.42 \mathrm{~mL}, 30.0 \mathrm{mmol})$ in chloroform $(20 \mathrm{~mL})$ was added dropwise over $30 \mathrm{~min}$, and the resulting mixture was stirred at $0{ }^{\circ} \mathrm{C}$ for $2 \mathrm{~h}$. After the mixture was allowed to warm to $25{ }^{\circ} \mathrm{C}$, the solution was washed with water twice and brine. The organic layer was dried with $\mathrm{Na}_{2} \mathrm{SO}_{4}$ and concentrated by a rotary evaporator. The crude product was dried in vacuo and purified by silica gel column chromatography eluted with ethyl acetate to yield a pale-yellow solid. The yield was $2.90 \mathrm{~g}$ (56\%). IR (neat, $\mathrm{cm}^{-1}$ ): 3263, 2960, 1746, 1643, 1544, 1272, 1200, 1152, 1033. ${ }^{1} \mathrm{H}$ NMR $\left(\mathrm{CDCl}_{3}, \mathrm{ppm}, 25{ }^{\circ} \mathrm{C}\right): \delta 6.82(\mathrm{~s}$, $2 \mathrm{H}), 4.55(\mathrm{~m}, 2 \mathrm{H}), 4.18(\mathrm{q}, J=6.9 \mathrm{~Hz}, 4 \mathrm{H}), 2.56(\mathrm{~m}, 4 \mathrm{H}), 1.69(\mathrm{~m}$, $2 \mathrm{H}), 1.57(\mathrm{~m}, 4 \mathrm{H}), 1.27(\mathrm{t}, J=6.9 \mathrm{~Hz}, 6 \mathrm{H}), 0.94(\mathrm{~d}, J=6.3 \mathrm{~Hz}$, 12H). ${ }^{13} \mathrm{C} \mathrm{NMR}\left(\mathrm{CDCl}_{3}, \mathrm{ppm}, 25{ }^{\circ} \mathrm{C}\right): \delta 173.36,172.13,61.16$, $50.96,40.93,31.74,24.73,22.74,21.67,14.01$.

\section{Synthesis of $N$-propargyl-t-alanine ethyl ester (2)}

A terminal modifier containing an alkyne group was synthesized by a modified protocol according a previously reported work. ${ }^{32}$ Anhydrous lithium hydroxide $(1.32 \mathrm{~g}$, $55 \mathrm{mmol}$ ), molecular sieves (4 ̊, $18.8 \mathrm{~g}$ ), and $N, N$-dimethylformamide $(150 \mathrm{~mL})$ were placed in a flask equipped with a stirring bar, and the mixture was stirred at $25{ }^{\circ} \mathrm{C}$ for $30 \mathrm{~min}$ under nitrogen. Propargyl bromide $(2.23 \mathrm{~mL}, 30 \mathrm{mmol})$ and 
L-alanine ethyl ester hydrochloride $(3.84 \mathrm{~g}, 25 \mathrm{mmol})$ were added to this dispersion, and the mixture was stirred at $25{ }^{\circ} \mathrm{C}$ for $12 \mathrm{~h}$. After the reaction, the inorganic salt and molecular sieves were removed by filtration. Ethyl acetate was added, and the organic solution was washed with water and brine. The organic layer was dried with $\mathrm{MgSO}_{4}$ and concentrated by a rotary evaporator. The crude product was dried in vacuo and purified by silica gel column chromatography eluted with hexane/ethyl acetate (1/1) to yield a pale-yellow liquid. The yield was $1.33 \mathrm{~g}$ (34\%). The spectroscopic data were identical to the reported values.

\section{Chemoenzymatic polymerization of $\mathrm{L}$-alanine ethyl ester with acrylamide derivative 1 using papain}

To a glass tube equipped with a stirring bar were added L-alanine ethyl ester hydrochloride $(0.922 \mathrm{~g}, 6.0 \mathrm{mmol}), 1$ (0.514 g, $3.0 \mathrm{mmol})$, phosphate buffer $(2.0 \mathrm{~mL}, 1.0 \mathrm{M}, \mathrm{pH} 8.0)$, and methanol $(1.0 \mathrm{~mL})$, and the mixture was stirred at $40{ }^{\circ} \mathrm{C}$ until all the substrates were completely dissolved. A solution of papain $(0.30 \mathrm{~g})$ in phosphate buffer $(2.0 \mathrm{~mL})$ was added to this solution in one portion. The final concentrations of alanine and papain were $1.0 \mathrm{M}$ and $50 \mathrm{mg} \mathrm{mL} \mathrm{m}^{-1}$, respectively. The mixture was stirred at $800 \mathrm{rpm}$ and $40{ }^{\circ} \mathrm{C}$ for $2 \mathrm{~h}$. After cooling to $25^{\circ} \mathrm{C}$, the precipitate was collected by centrifuging at 9000 $\mathrm{rpm}$ for $15 \mathrm{~min}$ at $4^{\circ} \mathrm{C}$. The crude was washed with deionized water and water/methanol (1/1 in volume) and lyophilized to provide the acrylamide-modified poly(L-alanine) (acryl-polyAla) as a white solid. The yield was $0.189 \mathrm{~g}$ (23.5\%). The chemoenzymatic polymerization of glycine ethyl ester hydrochloride, L-glutamic acid diethyl ester hydrochloride, L-tyrosine ethyl ester hydrochloride, or $N_{\varepsilon}$-Boc-protected L-lysine methyl ester hydrochloride with 1 using papain was also carried out under the same conditions. All the polymerizations were triplicated to determine the standard deviation.

\section{Chemoenzymatic polymerization of $\mathrm{L}_{\mathrm{L}}$-alanine ethyl ester with alkyne derivative 2 using papain}

To a glass tube equipped with a stirring bar were added L-alanine ethyl ester hydrochloride $(0.154 \mathrm{~g}, 1.0 \mathrm{mmol}), 2$ (0.031 g, $0.2 \mathrm{mmol}$ ), phosphate buffer $(0.33 \mathrm{~mL}, 1.0 \mathrm{M}, \mathrm{pH}$ $8.0)$, and methanol $(0.17 \mathrm{~mL})$, and the mixture was stirred at $40{ }^{\circ} \mathrm{C}$ until all the substrates were completely dissolved. A solution of papain $(0.050 \mathrm{~g})$ in phosphate buffer $(0.33 \mathrm{~mL})$ was added to this solution in one portion. The final concentrations of alanine and papain were $1.0 \mathrm{M}$ and $50 \mathrm{mg} \mathrm{mL}{ }^{-1}$, respectively. The mixture was stirred at $800 \mathrm{rpm}$ and $40{ }^{\circ} \mathrm{C}$ for $2 \mathrm{~h}$. After cooling to $25{ }^{\circ} \mathrm{C}$, the precipitate was collected by centrifuging at $9000 \mathrm{rpm}$ for $15 \mathrm{~min}$ at $4^{\circ} \mathrm{C}$. The crude product was washed twice with deionized water and lyophilized to provide the alkyne-modified poly(L-alanine) as a white solid. The yield was $0.017 \mathrm{~g}(17.7 \%)$.

\section{Thiol-ene reaction for conjugation between acryl-polyAla and 1-dodecanethiol}

Acryl-polyAla (0.05 g, $0.1 \mathrm{mmol}$ of acrylamide moiety), 1-dodecanethiol (24 $\mu \mathrm{L}, 0.1 \mathrm{mmol})$, and 1-butyl-3-methylimidazolium acetate (BMImOAc, $2.0 \mathrm{~mL}$ ) were added to a flask equipped with a stir bar and stopcock, and the mixture was sonicated until all the solid was dissolved. After 2,2'-azobis(isobutyronitrile) (AIBN, $0.016 \mathrm{~g}, 0.1 \mathrm{mmol}$ ) was added, the solution was deoxygenated by purging with nitrogen. The mixture was stirred at $60^{\circ} \mathrm{C}$ for $12 \mathrm{~h}$ under nitrogen. After cooling to $25^{\circ} \mathrm{C}$, the solution was poured into water. The precipitate was collected by centrifugation at $9000 \mathrm{rpm}$ for $15 \mathrm{~min}$ at $4{ }^{\circ} \mathrm{C}$, washed twice with water, and lyophilized to provide the product. The yield was $0.057 \mathrm{~g}(81 \%)$.

\section{Free-radical copolymerization of acryl-polyAla with $\mathrm{N}$-isopropylacrylamide (NIPAm)}

Acryl-polyAla (0.05 g, $0.1 \mathrm{mmol}$ of acrylamide moiety), NIPAm $(0.554 \mathrm{~g}, 4.9 \mathrm{mmol})$, and BMImOAc $(2.0 \mathrm{~mL})$ were added to a flask equipped with a stir bar and stopcock, and the mixture was sonicated until all the solid was dissolved. After AIBN (0.016 g, $0.1 \mathrm{mmol}$ ) was added, the solution was deoxygenated by purging with nitrogen. The resulting solution was then stirred at $60^{\circ} \mathrm{C}$ for $24 \mathrm{~h}$ under nitrogen. After cooling to $25^{\circ} \mathrm{C}$, the mixture was poured into cold water. An insoluble precipitate was removed by filtration at $0{ }^{\circ} \mathrm{C}$. The filtrate was then heated to $80^{\circ} \mathrm{C}$, and the precipitate was collected by filtration. The filtrate was washed with hot water several times and dried under vacuum to obtain the graft polymer poly(NIPAm- $g$-Ala) as a white solid. The yield was $0.1632 \mathrm{~g}$ (27\%). Poly $(N$-isopropylacrylamide) [poly(NIPAm)] as a control was also synthesized by radical polymerization using AIBN in BMImOAc under the same conditions.

\section{Turbidity measurement for the solution of poly(NIPAm- $g$-Ala)}

Poly(NIPAm- $g$-Ala) was dissolved in Milli-Q water (0.05 w/v\%) at $20{ }^{\circ} \mathrm{C}$. The solution was placed into a quartz cuvette with a $1 \mathrm{~mm}$ path length. The transmittance of the solution at $600 \mathrm{~nm}$ was obtained by a V-750 UV-visible spectrophotometer (JASCO, Tokyo, Japan) every $2{ }^{\circ} \mathrm{C}$ during a heating and cooling process. The sample was heated from 20 to $50{ }^{\circ} \mathrm{C}$ at a heating rate of $1^{\circ} \mathrm{C} \mathrm{min}{ }^{-1}$, maintained at $50{ }^{\circ} \mathrm{C}$ for $10 \mathrm{~min}$, and cooled down to $20^{\circ} \mathrm{C}$ at a cooling rate of $1^{\circ} \mathrm{C} \mathrm{min}^{-1}$. The data points were fit by a sigmoid function, and cloud points were determined from a threshold of the fitting curve. As a control, the same measurement was carried out with a solution of poly (NIPAm) $(0.05 \mathrm{w} / \mathrm{v} \%)$.

\section{Results and discussion}

\section{Chemoenzymatic polymerization}

The protease-catalyzed polymerization of amino acid esters can afford a broad spectrum of peptide sequences. Papain is a cysteine protease with relatively broad substrate specificity and has been used for the chemoenzymatic polymerization of various amino acid esters to date. Not only natural amino acids but also unnatural amino acids can be introduced into peptides via papain-catalyzed polymerization. ${ }^{19-21}$ Therefore, papain was used as a catalyst for the chemoenzymatic polymer- 
ization in this study. We selected an acryloyl group as a terminal functional group because it undergoes Michael addition reactions with thiol or amine groups and radical polymerization, enabling the peptides to be utilized as a building block for constructing special polymer architectures. A terminalmodifying agent containing the acryloyl group (1) was synthesized from acryl chloride and L-alanine ethyl ester (AlaOEt). Introduction of the Ala unit in the terminal-modifying agent is important for efficient recognition by proteases. For the one-pot synthesis of terminal-functionalized peptides, the papain-catalyzed polymerization of various amino acid esters was carried out at $40{ }^{\circ} \mathrm{C}$ in the presence of 1 in $1 \mathrm{M}$ sodium phosphate buffer (Scheme 1). A small amount of methanol (20 vol\%) was added to the reaction mixture to ensure the complete dissolution of the monomer and $\mathbf{1}$. We tried Ala-OEt, glycine ethyl ester (Gly-OEt), diethyl L-glutamate [Glu-(OEt) $)_{2}$, L-tyrosine ethyl ester (Tyr-OEt), and $N_{\varepsilon}$-Boc-protected L-lysine methyl ester [Lys(Boc)-OMe] as amino acid monomers to examine the versatility of this polymerization. The results of the papain-catalyzed polymerization are summarized in Table 1. First, the polymerization of Ala-OEt was carried out at various Ala-OEt/1 feed ratios (Runs 1-4). A white precipitate was gradually obtained within $2 \mathrm{~h}$ under all conditions, and

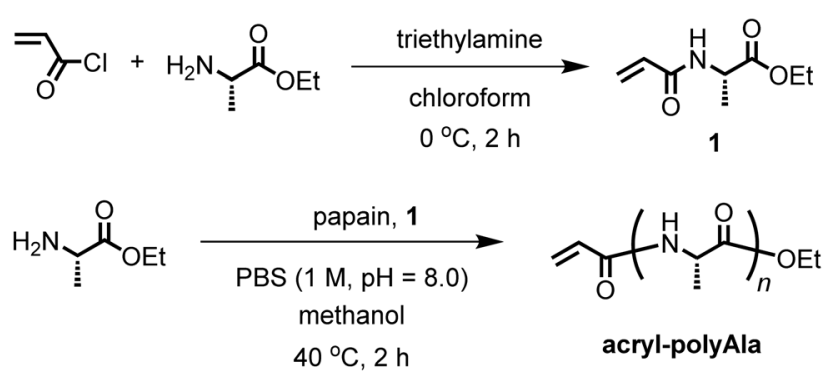

Scheme 1 Synthesis of an acrylamide terminal-modifying agent (1) and terminal-functionalized poly(L-alanine) via papain-catalyzed chemoenzymatic polymerization in the presence of 1 as a terminal modifier.

Table 1 Papain-catalyzed polymerization of amino acid esters in the presence of acrylamide derivative $1^{a}$

\begin{tabular}{lllll}
\hline & & & & $\begin{array}{l}\text { Terminal } \\
\text { modification } \\
\text { rate }^{c}(\%)\end{array}$ \\
\hline 1 & Ala-OEt & $1 / 0.1$ & Yield $^{b}(\%) /[\mathbf{1}]$ \\
2 & Ala-OEt & $1 / 0.3$ & $31.5 \pm 2$ & $18 \pm 2$ \\
3 & Ala-OEt & $1 / 0.5$ & $26.8 \pm 3$ & $68 \pm 1$ \\
4 & Ala-OEt & $1 / 1$ & $23.2 \pm 3$ & $78 \pm 4$ \\
5 & Gly-OEt & $1 / 1$ & $15.1 \pm 2$ & $>99$ \\
6 & Glu-(OEt $)_{2}$ & $1 / 1$ & 0 & - \\
7 & Tyr-OEt & $1 / 1$ & $13.8 \pm 4$ & $>99$ \\
8 & Lys(Boc)-OMe & $1 / 1$ & $7.9 \pm 1$ & $>99$ \\
& & & $55.3 \pm 2$ & $>99$
\end{tabular}

${ }^{a}$ Polymerization was carried out using monomer ( $\mathrm{HCl}$ salt, $1 \mathrm{M}$ ), acrylamide terminal modifier $1(0.1-1 \mathrm{M})$ and papain $\left(50 \mathrm{mg} \mathrm{mL}^{-1}\right)$ in phosphate buffer $(1 \mathrm{M}, \mathrm{pH} 8.0)$ and methanol at $40{ }^{\circ} \mathrm{C}$ for $2 \mathrm{~h}$. ${ }^{b}$ Precipitate was collected by centrifugation, washed with water, and lyophilized. ${ }^{c}$ Degree of terminal functionalization with acrylamide moiety was determined by ${ }^{1} \mathrm{H}$ NMR spectroscopy. the yield of the precipitate was $15.1-31.5 \%$. The yield slightly decreased when the amount of $\mathbf{1}$ in the feed increased because of the lower affinity of $\mathbf{1}$ than Ala-OEt for papain. In the chemoenzymatic polymerization, the aminolysis reaction is kinetically facilitated by the use of weakly activated ester derivatives of amino acids. The aminolysis reaction competes with hydrolysis reaction which decreases the molecular weight, especially at the latter stage of polymerization. ${ }^{19,20}$ The use of 1 with a lower affinity to papain probably retarded the copolymerization with Ala-OEt, resulting in lower yields compared to the homopolymerization of Ala-OEt. ${ }^{33,34}$ Using a suitable protease optimized by screening proteases including artificially modified ones can improve the yield and molecular weight of the resulting peptides.

The chemical structure of the obtained products was confirmed by matrix-assisted laser desorption/ionization time-offlight mass spectrometry (MALDI-TOF MS) and ${ }^{1} \mathrm{H}$ NMR spectroscopy. Fig. 1 shows the ${ }^{1} \mathrm{H}$ NMR spectra of poly(L-alanine) (polyAla) obtained by chemoenzymatic polymerization at different Ala-OEt/1 feed ratios (Run 1-4). In addition to the signals of the polyAla main chain, new signals derived from the vinyl protons of the acrylamide group (assigned as a, b, and $\mathrm{c}$ in Fig. 1) appear at 5.5-6.5 ppm in all the spectra. The terminal modification rate with the acrylamide group was cal-
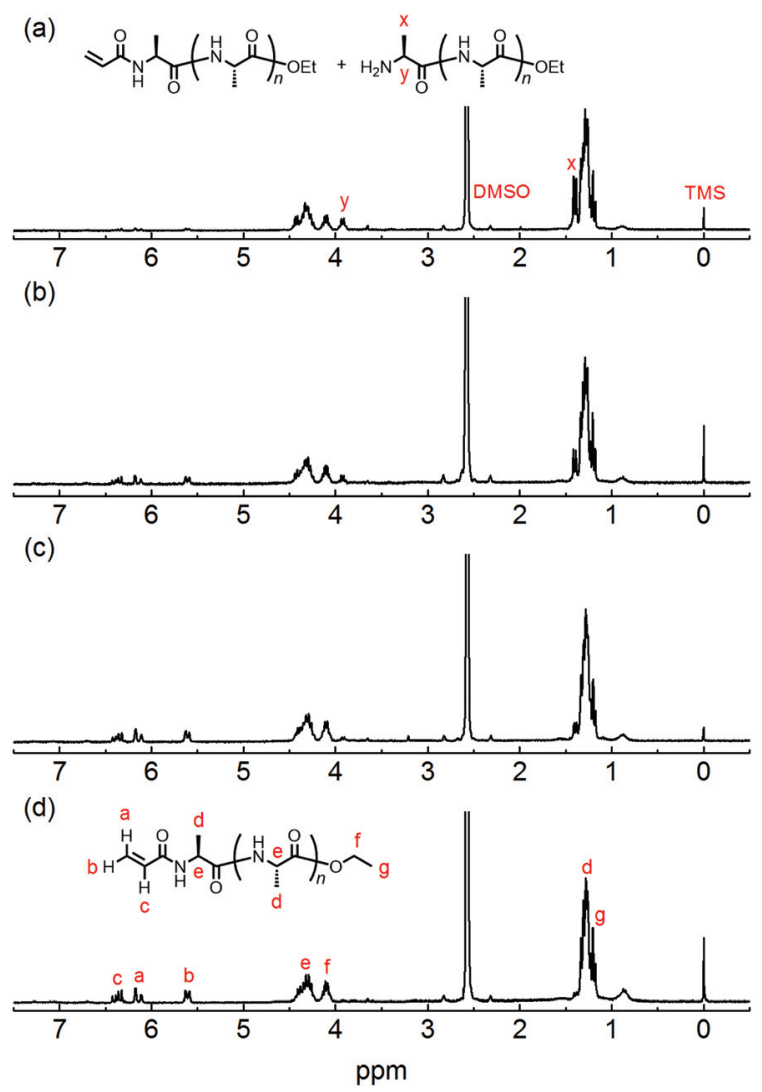

Fig. $1{ }^{1} \mathrm{H}$ NMR spectra of poly(L-alanine)s with an acrylamide moiety at the $\mathrm{N}$-terminus synthesized via papain-catalyzed polymerization at different Ala-OEt/1 feed ratios: (a) Ala-OEt/1 $=1 / 0.1$, (b) Ala-OEt/1 = 1/0.3, (c) Ala-OEt/1 = 1/0.5, and (d) Ala-OEt/1 = 1/1. 
culated by comparing the integral ratio of the vinyl protons with the methylene protons of the C-terminal ester group appearing at $4.2 \mathrm{ppm}$ (assigned as $\mathrm{f}$ in Fig. 1) and is listed in Table 1 . In the case of Ala-OEt/ $1=1 / 0.1$, the vinyl signals are small, and the terminal modification rate was $20 \%$. Increasing the amount of $\mathbf{1}$ in the feed composition increased the terminal modification rate, and almost complete modification was achieved at a feed ratio of Ala-OEt/1 $=1 / 1$. The MALDI-TOF MS spectrum of the obtained polyAla revealed that a series of peaks with an $\mathrm{m} / \mathrm{z}$ interval corresponding to the Ala monomer unit $(71.0 \mathrm{~m} / \mathrm{z})$ appeared, as shown in Fig. 2 (Run 4 in Table 1). The molecular mass of each peak was identical to polyAla containing an acrylamide unit and an ethyl ester unit at the $\mathrm{N}$ and C-termini, respectively, confirming the synthesis of acrylamide-terminated polyAla (acryl-polyAla) via chemoenzymatic polymerization. When the feed ratio of Ala-OEt/1 was in the range from $1 / 0.1$ to $1 / 0.5$, another series of major peaks appeared in addition to the peaks of acryl-polyAla (Fig. S3 $\dagger$ ). The molecular mass of these peaks corresponds to polyAla with a free amine $\mathrm{N}$-terminus and an ethyl ester C-terminus, indicating that the modification with acrylamide was insufficient under these conditions. The peak intensity of free amineterminated polyAla increased with a decrease in the feed amount of 1 , corresponding to the results of ${ }^{1} \mathrm{H}$ NMR spectroscopy. The peak corresponding to polyAla with a free amine $\mathrm{N}$-terminus was overlapping with the potassium ion adduct of the acrylamide-terminated polyAla as shown in Fig. 2b, indicating that there is a possibility that the product was still con-
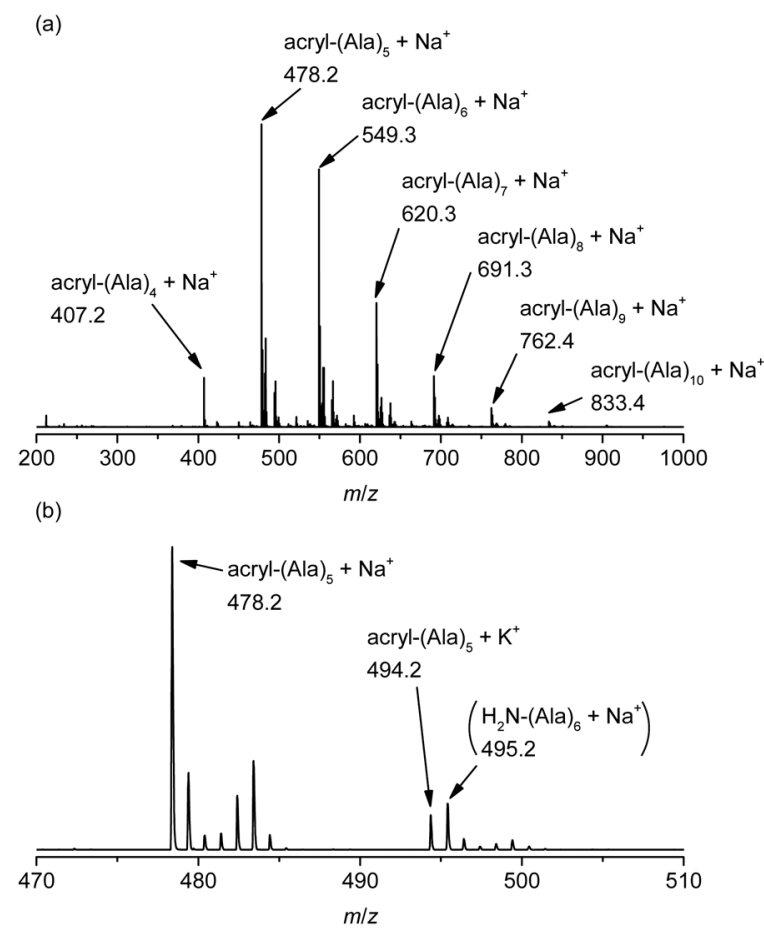

Fig. 2 (a) MALDI-TOF MS spectrum of poly(L-alanine)s with an acrylamide moiety at the $\mathrm{N}$-terminus synthesized via papain-catalyzed polymerization at an Ala-OEt/1 feed ratio of $1 / 1$ and (b) the expanded spectrum from 470 to $510 \mathrm{~m} / \mathrm{z}$. taminated with a small amount of polyAla with a free amine $\mathrm{N}$-terminus. However, judging from the integral ratio of ${ }^{1} \mathrm{H}$ NMR spectra, the terminal defect without the acrylamide moiety is almost negligible for the product prepared at the feed ratio of Ala-OEt/1 $=1 / 1$. The molecular weights detected in the MALDI-TOF MS spectra were in the range between 400 to 1000 Da regardless of the Ala-OEt/1 composition. PolyAla obtained under the same condition without $\mathbf{1}$ also showed a similar molecular weight distribution as previously reported. ${ }^{34}$ This indicates that the molecular weight obtained in the polymerization was mainly limited by precipitation of the product. However, a slight shift to lower molecular weight in the MALDI-TOF MS spectra was observed at a higher feed amount of $\mathbf{1}$. Therefore, $\mathbf{1}$ was assumed to function as an end-capper to decrease the molecular weight during the polymerization proceeding in a step-growth fashion. ${ }^{16}$ So far, the molecular weight obtained by the chemoenzymatic polymerization in aqueous media has reached up to approximately 2000 Da depending on the amino acid residues that characterize the reactivity of monomers and the solubility of resulting polypeptides in water. ${ }^{29}$ The use of water-free conditions such as solution polymerization in an organic solvent ${ }^{35}$ or bulk polymerization ${ }^{36}$ can improve the molecular weight of the obtained polypeptides, although the greenness of the chemoenzymatic synthesis is deteriorated.

The papain-catalyzed polymerization in the presence of $\mathbf{1}$ was also applied to other amino acid esters. All the polymerization reactions afforded a white precipitate except for Gly-OEt. This result is probably because of the low affinity of Gly compared to Ala for papain. ${ }^{33}$ Poly(ethyl L-glutamate) (polyGlu), poly(L-tyrosine) (polyTyr), and poly( $N_{\varepsilon}$-Boc-L-lysine) (polyLys) were successfully obtained with yields of $13.8,7.9$, and $55.3 \%$, respectively. The yield of polyLys was relatively high compared to the other amino acid monomers. This is due to the high hydrophobic structure of $N_{\varepsilon}$-Boc-protected Lys which facilitates the precipitation of resulting polyLys. The chemical structures of the obtained peptides, which were characterized by ${ }^{1} \mathrm{H}$ NMR spectroscopy and MALDI-TOF mass spectrometry, revealed that all the peptides possess an acrylamide group at the $\mathrm{N}$-terminus (Fig. S4-S9†). Notably, the Tyr ester can also be polymerized via chemoenzymatic polymerization; by contrast, protection of the phenolic hydroxy group is unavoidable for synthesizing the well-defined terminal-functionalized polyTyr by conventional polymerization methods such as ring-opening polymerization of NCAs. ${ }^{37-39}$ There are very few examples that employed unprotected Lys NCA derivative for the polymerization. ${ }^{40}$ A series of major peaks in the MALDI-TOF MS spectrum were assigned to polyTyr with an acrylamide terminus, confirming that the N-terminus of polyTyr was completely modified with the acrylamide group via one-pot chemoenzymatic synthesis without any protection of the side groups.

\section{Chemoenzymatic synthesis of alkyne-modified polyAla}

We synthesized another terminal-modifying agent, 2, containing an alkyne moiety as a functional group. Terminal modifier 2 consists of an alanine ethyl ester moiety for effective recognition by papain during chemoenzymatic polymerization. 


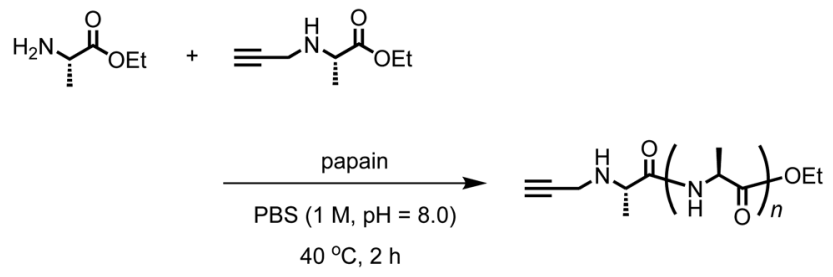

Scheme 2 One-pot chemoenzymatic synthesis of poly(L-alanine) functionalized with an alkyne moiety at the $\mathrm{N}$-terminus.

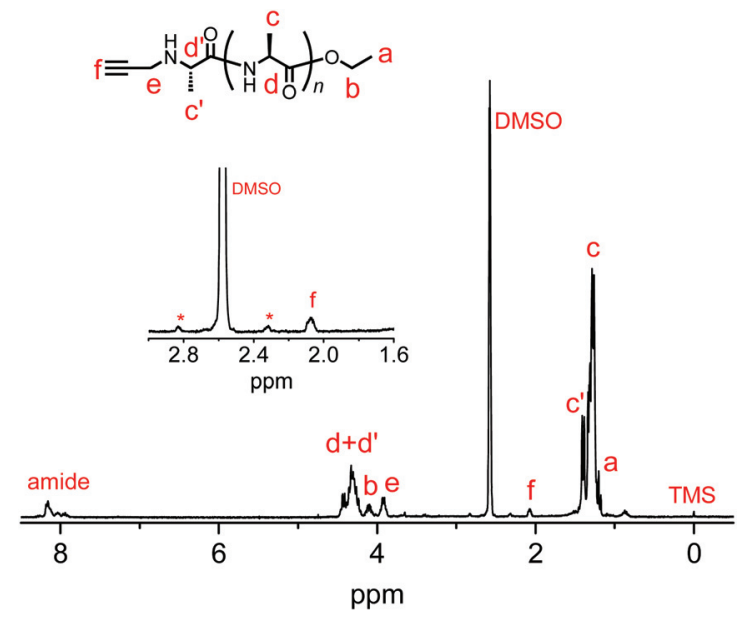

Fig. $3{ }^{1} \mathrm{H}$ NMR spectrum of poly(L-alanine) with an alkyne moiety at the $\mathrm{N}$-terminus synthesized via papain-catalyzed polymerization at the Ala$\mathrm{OEt} / 2$ feed ratio of $1 / 0.2$. Asterisk shows spinning side bands of solvent peak.

The papain-catalyzed polymerization of Ala-OEt was performed in the presence of 2 under the optimized conditions (Scheme 2). Alkyne-modified polyAla was obtained as a white precipitate in $17.7 \%$ yield. The chemical structure of alkynemodified polyAla was analyzed by ${ }^{1} \mathrm{H}$ NMR spectroscopy (Fig. 3). A characteristic signal assignable to a proton of the propargyl group appeared at $2.1 \mathrm{ppm}$, confirming the introduction of the alkyne moiety at the N-terminus of polyAla.

\section{Conjugation using the acrylamide terminal group of polyAla}

The vinyl group in the acrylamide terminal group of acrylpolyAla can be used as a conjugation site, which results in blocky structures. We attempted the radical-mediated thiolene addition reaction between the acrylamide moiety of acrylpolyAla and 1-dodecanethiol (Scheme 3). The reaction was performed in the presence of AIBN in 1-butyl-3-methylimidazolium acetate (BMImOAc), an ionic liquid that is known to dissolve cellulose and polypeptides. The chemical structure of the resulting polyAla conjugated with 1-dodecanethiol was characterized by ${ }^{1} \mathrm{H}$ NMR spectroscopy and MALDI-TOF MS spectrometry (Fig. 4). The MALDI-TOF MS spectrum of the obtained polyAla showed a series of peaks with an $\mathrm{m} / \mathrm{z}$ interval corresponding to the Ala monomer unit $(71.0 \mathrm{~m} / \mathrm{z})$. Compared to the peaks of acryl-polyAla in Fig. 2, all the peaks shifted to higher

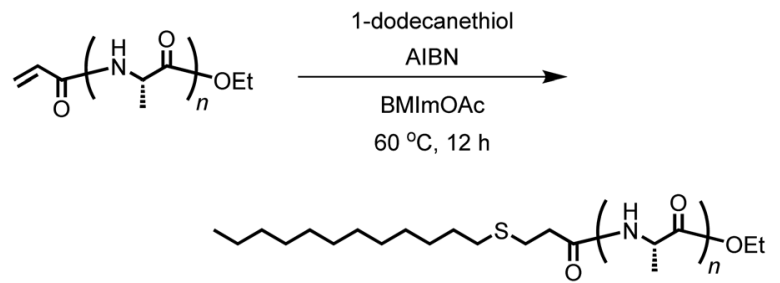

Scheme 3 Conjugation of acryl-polyAla with a thiol derivative via a radical-mediated thiol-ene reaction.

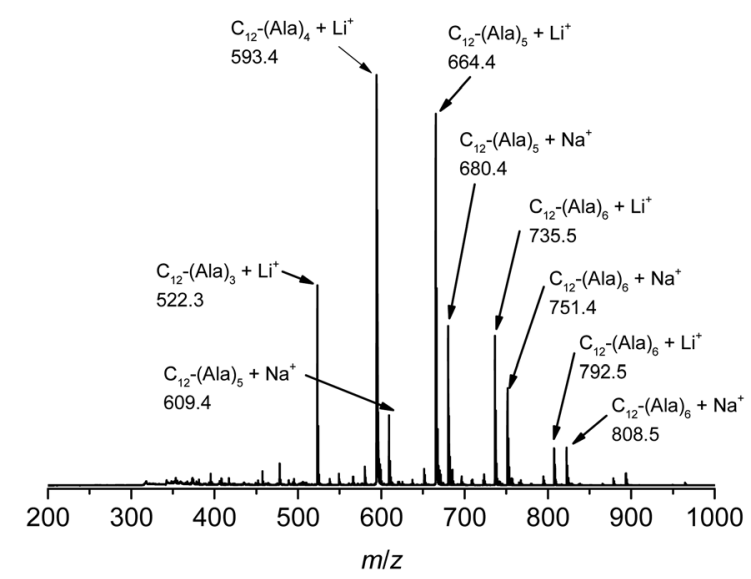

Fig. 4 MALDI-TOF MS spectrum of poly(L-alanine)s conjugated with 1-dodecanthiol at the acrylamide $\mathrm{N}$-terminal.

mass values by $202.2 \mathrm{~m} / \mathrm{z}$, which corresponds to the mass of 1-dodecanethiol. This result indicates that complete conjugation with a thiol derivative was achieved via a thiol-ene reaction.

\section{Postpolymerization of acrylamide-terminated polyAla}

The acrylamide moiety is a group that is polymerizable via radical or anionic polymerization. The peptides with the acrylamide group at the $\mathrm{N}$-terminus synthesized in this work can be used as a macromonomer for radical polymerization, which results in the formation of graft polymers. ${ }^{41,42}$ We attempted the free radical polymerization of acryl-polyAla in the presence of AIBN as a radical initiator. To completely dissolve the acrylpolyAla macromonomer, BMImOAc was used as a reaction medium. Unfortunately, the homopolymerization of acrylpolyAla failed due to the high viscosity of the polymer solution. Therefore, $N$-isopropylacrylamide (NIPAm) was copolymerized with acryl-polyAla using AIBN in BMImOAc (Scheme 4). The copolymerization in the ionic liquid successfully proceeded to afford the graft copolymer poly(NIPAm- $g$-Ala). The numberaverage molecular weight $\left(M_{\mathrm{n}}\right)$ and the molecular weight dispersity $\left(M_{\mathrm{w}} / M_{\mathrm{n}}\right)$ estimated by GPC were 35000 Da and 1.46, respectively. Poly(NIPAm) was also synthesized via radical polymerization in BMImOAc for comparison $\left(M_{\mathrm{n}}=73000 \mathrm{Da}\right.$; $\left.M_{\mathrm{w}} / M_{\mathrm{n}}=1.52\right)$. The structure of poly(NIPAm- $g$-Ala) was confirmed by ${ }^{1} \mathrm{H}$ NMR spectroscopy (Fig. S11†). The GPC trace poly(NIPAm-g-Ala) was unimodal and showed a shift to lower molecular weight compared to that of poly(NIPAm) prepared at 


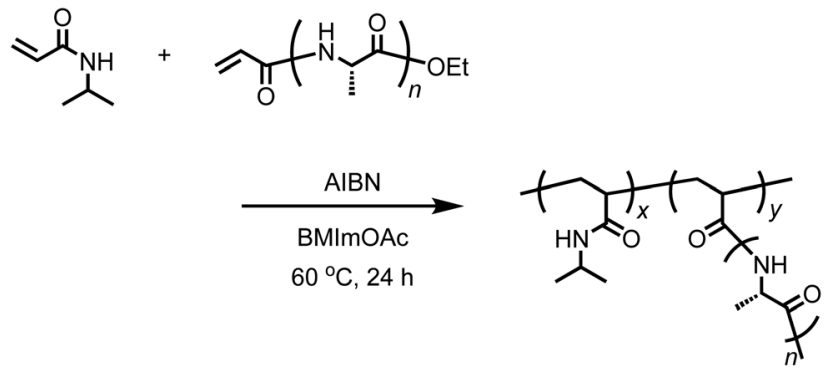

Scheme 4 Free radical copolymerization of acryl-polyAla with NIPAm.

the same condition (Fig. S12 $\dagger$ ). This fact indicates that the poly(NIPAm-g-Ala) assumedly possesses a branched structure which has smaller hydrodynamic radius than the linear poly (NIPAm).

CD spectroscopic analysis was performed on aqueous solutions of poly(NIPAm- $g$-Ala) and poly(NIPAm). The resulting CD spectrum of poly(NIPAm- $g$-Ala) showed a Cotton effect with a small positive peak at $215 \mathrm{~nm}$ and a large negative peak at $195 \mathrm{~nm}$, whereas no peak appeared in the spectrum of poly (NIPAm) (Fig. S12†). This result indicates that optically active polyAla was successfully incorporated into the polyNIPAm backbone via radical copolymerization of the acryl-polyAla macromonomer. The CD spectrum of poly(NIPAm- $g$-Ala) was characterized as a typical random coil structure. ${ }^{43}$ Therefore, the polyAla grafts did not adopt any secondary structures under the solubilized, dispersed condition in an aqueous media, although polyAla generally tends to form $\beta$-sheet structure in natural structural proteins. ${ }^{44,45}$

Poly(NIPAm) is known to show a lower critical solution temperature (LCST) at approximately $32{ }^{\circ} \mathrm{C}$ due to its coilglobule transition caused by dehydration of the polymer chains. ${ }^{46-48}$ We investigated the effect of polyAla grafts on the physical properties of poly(NIPAm) by measuring the turbidity of polymer solutions in water. The aqueous solutions of poly (NIPAm- $g$-Ala) and poly(NIPAm) were subjected to a heating and cooling cycle at a rate of $1{ }^{\circ} \mathrm{C} \min ^{-1}$, and the transmittance of the solutions was monitored, as shown in Fig. 5. A steep decrease in transmittance was observed at 32.0 and $31.8^{\circ} \mathrm{C}$ for polyNIPAm and poly(NIPAm- $g$-Ala) in the heating process, respectively, indicating that both polymers showed a cloud point attributable to the coil-globule transition of the poly(NIPAm) chains. In the case of poly(NIPAm), a slightly lower cloud point at $26.2{ }^{\circ} \mathrm{C}$ was observed in the cooling process. This hysteresis is caused by weak crosslinking via hydrogen bonding between amide bonds in the globule state, as reported in previous studies. ${ }^{49,50}$ In contrast, poly(NIPAm- $g$-Ala) showed a lower cloud point at $24.2^{\circ} \mathrm{C}$ than poly(NIPAm), indicating a large hysteresis. The cloud point of polymers showing an LCST highly depends on their chemical structures; however, the introduction of polyAla grafts at the poly(NIPAm) side chains only affected the cloud point in the cooling process. This fact indicates that aggregates of the polyAla fragments are assumed to function as cross-linking points in the globule
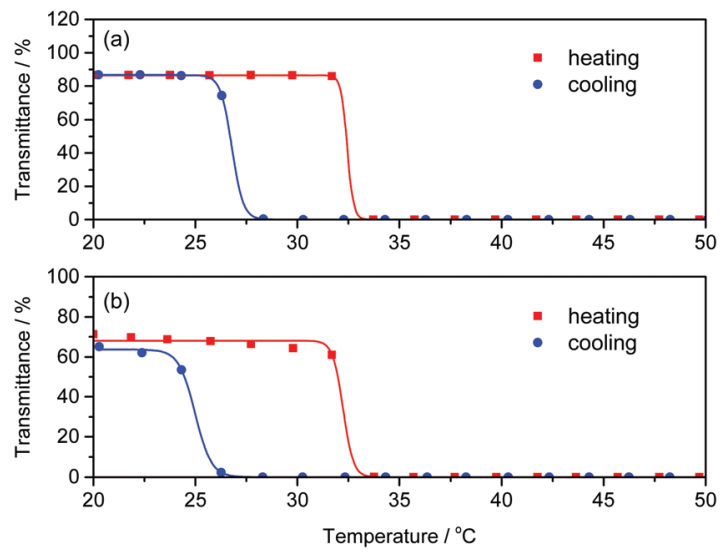

Fig. 5 Temperature dependence of transmittance at $600 \mathrm{~nm}$ for (a) poly(NIPAm) and (b) poly(NIPAm-g-Ala) aqueous solutions (1 wt\%) in the heating (red) and cooling (blue) scan at a rate of $1^{\circ} \mathrm{C} \mathrm{min}^{-1}$.

states at a high temperature above the LCST. The transmittance of the poly(NIPAm- $g$-Ala) solution after the heating-to-cooling cycle became slightly lower than the initial transmittance, also indicating the aggregation of the polyAla fragments.

\section{Conclusions}

In conclusion, we successfully synthesized various oligomeric peptides modified with an acrylamide functional group at the $\mathrm{N}$-terminus via chemoenzymatic polymerization catalyzed by papain in the presence of an acrylamide terminal-modifying agent. The acrylamide group was introduced at the polyTyr $\mathrm{N}$-terminus in a one-pot chemoenzymatic synthesis without interacting with the side groups of the Tyr residues, enabling the direct synthesis of a functional peptide with unprotected side groups. Using an alkyne-containing terminal-modifying agent can also introduce an alkyne group at the N-terminus of polyAla. This result indicates that chemoenzymatic one-pot synthesis offers a wide variety of peptide structures. The conjugation of acryl-polyAla with a thiol derivative completely proceeded at the acrylamide moiety via a radical-mediated thiolene reaction, which is beneficial for the facile synthesis of block copolymers based on peptides. The obtained acrylamide-modified polyAla was further utilized as a macromonomer to prepare a graft copolymer containing polyAla side chains via radical copolymerization with NIPAm. The graft copolymer poly(NIPAm- $g$-Ala) showed different LCST behavior from poly(NIPAm), probably due to the aggregation of the polyAla side chains. These results strongly suggest that our methodology for synthesizing terminal-functionalized peptides is a promising tool for constructing various polymeric architectures based on peptide building blocks.

\section{Conflicts of interest}

There are no conflicts to declare. 


\section{Acknowledgements}

This work was financially supported by JST ERATO Grant Number JPMJER1602 and Grants-in-Aid for Young Scientists (B) (17K18361) from the Japan Society for the Promotion of Science (JSPS).

\section{Notes and references}

1 B. Merrifield, Science, 1986, 232, 341-347.

2 G. J. M. Habraken, A. Heise and P. D. Thornton, Macromol. Rapid Commun., 2012, 33, 272-286.

3 T. J. Deming, Prog. Polym. Sci., 2007, 32, 858-875.

4 M. P. Lutolf and J. A. Hubbell, Nat. Biotechnol., 2005, 23, 47-55.

5 K. P. McGrath, M. J. Fournier, T. L. Mason and D. A. Tirrell, J. Am. Chem. Soc., 1992, 114, 727-733.

6 A. Harada and K. Kataoka, Polym. J., 2017, 50, 95.

7 C. A. Machado, I. R. Smith and D. A. Savin, Macromolecules, 2019, 52, 1899-1911.

8 V. Mikhalevich, I. Craciun, M. Kyropoulou, C. G. Palivan and W. Meier, Biomacromolecules, 2017, 18, 3471-3480.

9 D. J. Adams and P. D. Topham, Soft Matter, 2010, 6, 37073721.

10 Y. Bae and K. Kataoka, Adv. Drug Delivery Rev., 2009, 61, 768-784.

11 A. Lavasanifar, J. Samuel and G. S. Kwon, Adv. Drug Delivery Rev., 2002, 54, 169-190.

12 H. Robson Marsden and A. Kros, Macromol. Biosci., 2009, 9, 939-951.

13 K. Wu, J. Yang, Č. Koňák, P. Kopečková and J. Kopeček, Macromol. Chem. Phys., 2008, 209, 467-475.

14 F. Sanda, G. Gao and T. Masuda, Macromol. Biosci., 2004, 4, 570-574.

15 K. Tsuchiya, Y. Miyagi, T. Miyamoto, P. G. Gudeangadi and K. Numata, in Enzymatic Polymerization towards Green Polymer Chemistry, ed. S. Kobayashi, H. Uyama and J. Kadokawa, Springer, Singapore, 2019, ch. 8, pp. 233-265.

16 K. Tsuchiya and K. Numata, Macromol. Biosci., 2017, 17, 1700177.

17 J. Gimenez-Dejoz, K. Tsuchiya and K. Numata, ACS Chem. Biol., 2019, 14, 1280-1292.

18 K. Numata, Polym. J., 2015, 47, 537-545.

19 K. Tsuchiya and K. Numata, in Green Polymer Chemistry: New Products, Processes, and Applications, American Chemical Society, 2018, vol. 1310, ch. 7, pp. 95-105.

20 K. Tsuchiya and K. Numata, Chem. Commun., 2017, 53, 7318-7321.

21 K. Yazawa, J. Gimenez-Dejoz, H. Masunaga, T. Hikima and K. Numata, Polym. Chem., 2017, 8, 4172-4176.

22 K. Yazawa and K. Numata, Polymers, 2016, 8, 194.

23 K. Tsuchiya, H. Masunaga and K. Numata, Biomacromolecules, 2017, 18, 1002-1009.

24 K. Tsuchiya and K. Numata, Macromol. Biosci., 2016, 16, 1001-1008.
25 K. Tsuchiya, N. Kurokawa, J. Gimenez-Dejoz, P. G. Gudeangadi, H. Masunaga and K. Numata, Polym. J., 2019, DOI: 10.1038/ s41428-019-0242-z.

26 J. M. Ageitos, J.-A. Chuah and K. Numata, Macromol. Biosci., 2015, 15, 990-1003.

27 J. M. Ageitos, P. J. Baker, M. Sugahara and K. Numata, Biomacromolecules, 2013, 14, 3635-3642.

28 K. Tsuchiya and K. Numata, ACS Macro Lett., 2017, 6, 103106.

29 P. G. Gudeangadi, K. Tsuchiya, T. Sakai and K. Numata, Polym. Chem., 2018, 9, 2336-2344.

30 T.-B. Yu, J. Z. Bai and Z. Guan, Angew. Chem., Int. Ed., 2009, 48, 1097-1101.

31 O. Rathore and D. Y. Sogah, J. Am. Chem. Soc., 2001, 123, 5231-5239.

32 Q. Yang, Y.-Y. Lai, W.-J. Xiao and H. Alper, Tetrahedron Lett., 2008, 49, 7334-7336.

33 J. M. Ageitos, K. Yazawa, A. Tateishi, K. Tsuchiya and K. Numata, Biomacromolecules, 2016, 17, 314-323.

34 P. J. Baker and K. Numata, Biomacromolecules, 2012, 13, 947-951.

35 I. S. Aguirre-Díaz, C. Montiel, I. Bustos-Jaimes, Y. MedinaGonzalez, A. Tecante and M. Gimeno, RSC Adv., 2018, 8, 35936-35945.

36 F. Totsingan, R. Centore and R. A. Gross, Chem. Commun., 2017, 53, 4030-4033.

37 C. Rosu, R. Cueto and P. S. Russo, Langmuir, 2016, 32, 8392-8402.

38 H. Wang, L. Tang, C. Tu, Z. Song, Q. Yin, L. Yin, Z. Zhang and J. Cheng, Biomacromolecules, 2013, 14, 3706-3712.

39 R. K. Scheule, F. Cardinaux, G. T. Taylor and H. A. Scheraga, Macromolecules, 1976, 9, 23-33.

40 A. Saha, T. K. Paira, M. Biswas, S. Jana, S. Banerjee and T. K. Mandal, J. Polym. Sci., Part A: Polym. Chem., 2015, 53, 2313-2319.

41 N. Hadjichristidis, M. Pitsikalis, H. Iatrou and S. Pispas, Macromol. Rapid Commun., 2003, 24, 979-1013.

42 K. Matyjaszewski, K. L. Beers, A. Kern and S. G. Gaynor, J. Polym. Sci., Part A: Polym. Chem., 1998, 36, 823-830.

43 J. T. Yang, C.-S. C. Wu and H. M. Martinez, in Methods in Enzymology, Academic Press, 1986, vol. 130, pp. 208-269.

44 C. Riekel, C. Bränden, C. Craig, C. Ferrero, F. Heidelbach and M. Müller, Int. J. Biol. Macromol., 1999, 24, 179186.

45 J. M. Gosline, P. A. Guerette, C. S. Ortlepp and K. N. Savage, J. Exp. Biol., 1999, 202, 3295-3303.

46 H. Kojima, Polym. J., 2018, 50, 411-418.

47 T. Kawaguchi, Y. Kojima, M. Osa and T. Yoshizaki, Polym. J., 2008, 40, 455.

48 M. Ito and T. Ishizone, J. Polym. Sci., Part A: Polym. Chem., 2006, 44, 4832-4845.

49 H. Lai, G. Chen, P. Wu and Z. Li, Soft Matter, 2012, 8, 26622670.

50 H. Cheng, L. Shen and C. Wu, Macromolecules, 2006, 39, 2325-2329. 